\title{
Modeling the superstorm in the 24th solar cycle
}

\author{
Emre Eroglu*
}

\begin{abstract}
:
The St. Patrick's Day phenomenon is a geomagnetic storm that deserves serious discussion because of its intensity and effectiveness. This study focuses on the St. Patrick's Day storm on March 17, 2015, which is the first big storm of the 24th solar cycle. The data obtained from various spacecrafts observing the ionosphere reveal the reputation and the strength of the storm. The author tries to discuss the event as a whole with all its parameters. Variables of the study are the solar wind parameters and zonal geomagnetic indices. Models with solar wind pressure, proton density and magnetic field may aid in making the dynamic structure of the phenomenon more understandable. The obtained models are able to give the reader an idea of the results even if the storm prediction percentage is low. The author has endeavored to obey the cause-effect relationship without ignoring the physical principles when establishing mathematical models. Despite the fact that the relations between variables have poor correlation or have low statistical significance, in order to introduce the physical point of view they have not been ignored. This study puts forth a new mathematical perspective by discussing and visualizing what happened in the phenomenon.s
\end{abstract}

Keywords: Mathematical modeling, Zonal geomagnetic indices, Solar wind parameters

\section{Introduction}

The St. Patrick's Day geomagnetic storm is one of the most remarkable storms in the 24th solar cycle. The phenomenon has caused serious negative effects on the Earth. One of the reasons that make the storm interesting and important is the magnitude of the storm, and the other one is it has not been forecasted.

If one tries to reveal scientific results about geomagnetic storms, he/she should determine the relationship between solar wind parameters and zonal geomagnetic indices. With these two types of variables, the model may be established and the storm can be discussed provided that it obeys physical principles. The zonal geomagnetic indices, which are caused by solar parameter variables such as magnetic field, electric field, dynamic pressure, proton density due to the storm, have been in use since ancient times. Based on these variables, scientists can characterize the magnetosphere (Mayaud 1980; Fu et al.

*Correspondence: eroglumre@gmail.com

Department of Mathematics, Kirklareli University, Kayali Campus, 39100 Kirklareli, Turkey 2010a, b; Rathore et al. 2014). The geomagnetic storms, which have three phases including a sudden commencement, a main phase and a recovery phase, are one of the most important actions involving dynamic structures (Akasofu 1964; Burton et al. 1975). The storm reaction of the dynamic structure starts with coronal mass ejection (CME). During the CME pulse, large solar plasma clouds with an average speed of $800 \mathrm{~km} / \mathrm{s}$ seriously affect magnetosphere, leaving its place to define the magnetic activity indices that determine the reflex of the geomagnetic storm. Magnetic activity indices such as AE (auroral electrojet), ap, Kp (planetary index) and Dst (disturbance storm time) are described to specify the effects of the geomagnetic storm. AE is the hourly auroral electrojet index, ap is the planetary index derived from $\mathrm{Kp}$, and $\mathrm{Kp}$ is the quasi-logarithmic planetary index. The author utilizes hourly versions of $\mathrm{AE}$ and $\mathrm{Kp}$ indices. Dst, which exhibits the level of the magnetic storm (Hanslmeier 2007), is the hourly index related to the ring current. Kp, ap and Dst indices are generally used to define a magnetic storm (Mayaud 1980; Kamide et al. 1998; Joshi et al. 2011; Elliott et al. 2013). The St. Patrick's Day storm started on March 17 with CME. CME usually causes 
sudden increases in solar wind dynamic pressure. The reason for the formation of CMEs is the regional reconnections in the solar corona (Lin and Forbes 2000). These reconnections are the result of magnetic-field-line merging (Fu et al. 2011, 2012, 2013a, b, 2015, 2017). During the eruption, the light isotopes and plasmas in the solar corona are spread throughout the solar magnetic field. The charged particles interact with the Earth's magnetic field, causing intermittent disturbance of the ionosphere and magnetosphere (Fu et al. 2011, 2012, 2013b). Some observational (Zic et al. 2015; Manoharan et al. 2017; Subrahmanya et al. 2017) evidences suggested that the ionospheric disturbance dynamo had a significant effect on storm-time ionospheric electric fields at medium and low latitudes (Blanc and Richmond 1980). The CME leads directly to the change in solar wind parameters (Gonzalez et al. 1999).

Mathematical models give information to researchers about variables and their relationships, even if they are in different scientific areas (Ak et al. 2012; Celebi et al. 2014; Eroglu et al. 2016). In addition, they should give clues about the behavior of the variables under different circumstances and varied plasma-dense medium. Investigation of the evolution of dense plasmas over time cannot be limited to a single event. Because of their dynamic structures, establishing models will benefit scientists (Sibeck et al. 1991). Dynamic models have been used in many previous studies to describe global loading and unloading operations in storms (Burton et al. 1975; Baker et al. 1990; Dungey 1961; Gonzalez et al. 1994; Sugiura 1964; Temerin and Li 2002; Tsyganenko et al. 2003; Fu et al. 2014). Previously applied models can also be seen in this storm. For example, Wu and Leping (2016) have applied Gilmore et al. (2002) formula to St. Patrick's Day storm for Dst and $B_{\mathrm{z}}$.

The effects of the storm in all longitudinal sectors are characterized using spherical and regional electric current. Estimation of ionospheric current density can minimize the negative effects of substorm activity. The improvement of high-latitude ionospheric convection models aids in predicting substorm events (Chen et al. 2016). The effects of the magnetospheric convection electric field and the disturbing dynamo electric field at low latitudes were previously investigated (Fu et al. 2010a, b; Nava et al. 2016). The magnetic field oscillations of the Earth are seen at the same time in the Asian, African and American sectors during the southward orientation of the $B_{\mathrm{z}}$ component in the interplanetary magnetic field. The ionospheric irregularities at the high latitudes associated with auroral activities have been studied by Cherniak and Zakharenkova (2015).
The St. Patrick's Day geomagnetic storm (Astafyeva et al. 2015; Cherniak et al. 2015; Baker et al. 2016; Gvishiani et al. 2016; Nayak et al. 2016) has been widely studied during the past 2 years. It is necessary to understand the complex effects of the geomagnetic storm and predict the event based on the solar wind and IMF parameters. We focus on the variables of the phenomenon and discuss mathematical models. Binary linear models have difficulty in explaining the exact relationship between variables. Nevertheless, the presentation of these models is important (Eroglu 2018). Weak correlation inspires scientists to search for linear and nonlinear models. All approaches have exact obedience cause-effect relationship, and the causality principle governs linear and nonlinear models (Tretyakov and Erden 2008; Eroglu et al. 2012). The cause-effect relation should be thought of as an inseparable duo. The solar wind plasma parameters [the magnetic field $\left(B_{\mathrm{z}}\right)$, the electric field $(E)$, the solar wind dynamic pressure $(P)$, the proton density $(N)$, the flow velocity $(v)$ and the temperature $(T)$ ] of the phenomenon are the "cause." The zonal geomagnetic indices (Dst, ap, Kp and AE) of the storm are the "effect."

This paper uses the solar wind parameters $(P, v, E$, $T, N, B_{\mathrm{z}}$ ) and zonal geomagnetic indices (Dst, AE, Kp, ap). The author utilizes hourly versions of $\mathrm{AE}$ and $\mathrm{Kp}$ indices. In order to better interpret the first intense $(-250 \mathrm{nT} \leq$ Dst $<-100 \mathrm{nT})$ storm of the 24th solar cycle (March 17, 2015), solar wind parameters and zonal indices are analyzed in depth and linear and nonlinear models are established. The models support the previous work conducted by Eroglu (2018).

In "Data" section the solar parameters, zonal geomagnetic indices and a five-day distribution of variables are presented. In "Mathematical modeling" and "Conclusion" sections, the analyses are performed and discussion is given, respectively.

\section{Data}

Space Physics Environment Data Analysis Software (SPEDAS) is used in this research. Analysis software data are IDL based. It is accessible at the link below: http://themis.igpp.ucla.edu/software.shtml. The hourly OMNI-2 Solar Wind and IMF parameter data are accessible online. In addition, the $\mathrm{AE}$ and Dst indexes are taken from World Data Center for Geomagnetism, Kyoto, by using SPEDAS. Kp and ap are taken from NGDC by using SPEDAS with CDA Web Data Chooser (space physics public data). For March 2015 severe storm, solar wind dynamic pressure, IMF, electric field, flow speed and proton density were recorded in the OMNI hourly data. Geomagnetic storms are classified according to the intensity of the Dst index (Loewe and Prölss 1997). If the Dst index 


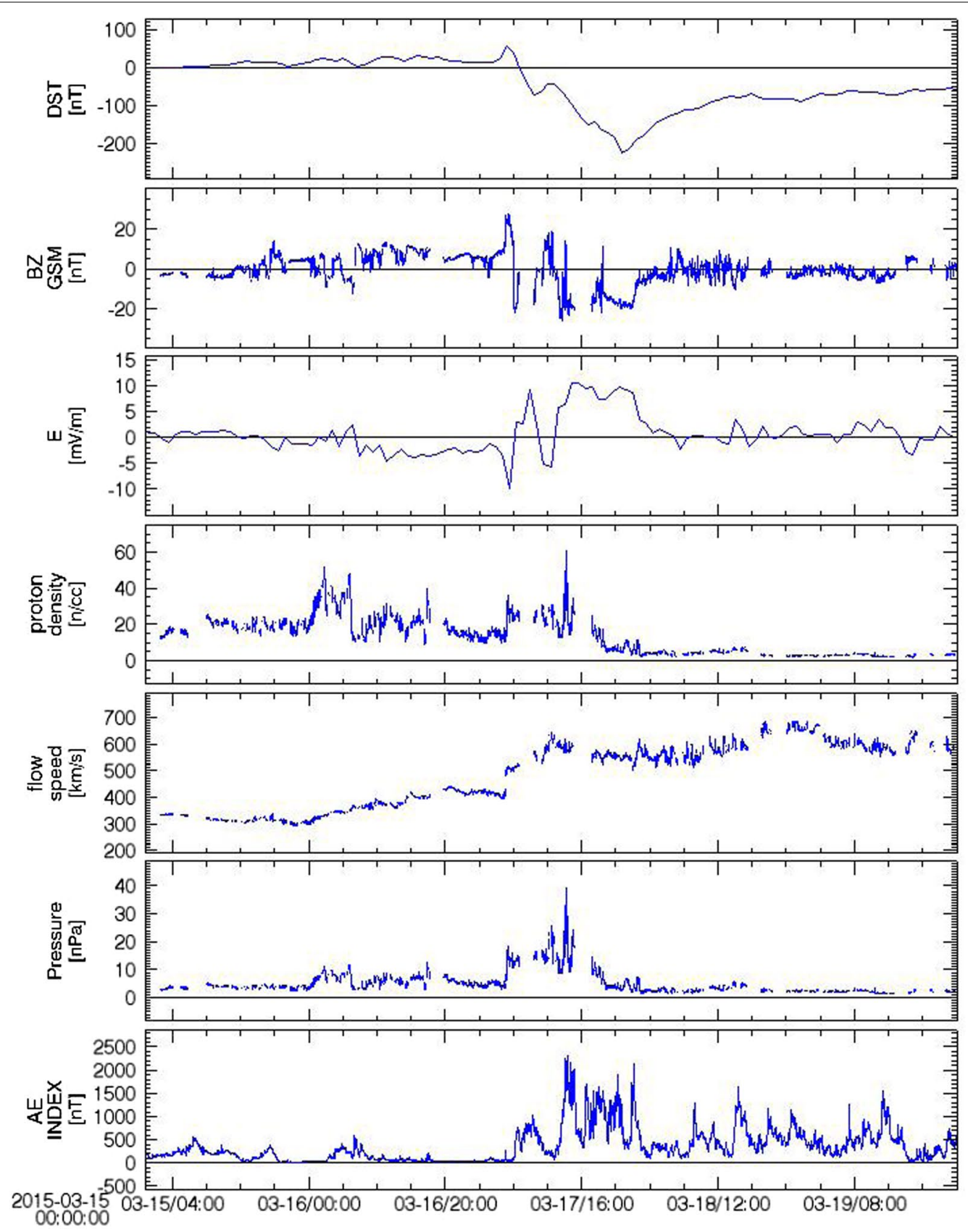

Fig. 1 From top to bottom the parameters shown are Dst index, $B_{z}$ magnetic field $(\mathrm{nT})$, E electric field $(\mathrm{mV} / \mathrm{m})$, proton density $N\left(1 / \mathrm{cm}^{3}\right)$, solar wind dynamic pressure $P(\mathrm{nPa})$, flow speed $v(\mathrm{~km} / \mathrm{s})$ and auroral electrojet AE (nT) index for March 15-19, 2015 (from NASA NSSDC OMNI data set). The characteristic storm at the intense level (Dst $=-223$ nT) on March 17, 2015, has been analyzed. Figure 1 shows the OMNI data set from 00 UT March 15, 2015, to 00 UT March 19, 2015. The plot interval covers the storm day (March 17, 2015), 2 days before and 2 days after (120 h) the storm

is between -50 and $-30 \mathrm{nT}$ this indicates a weak storm. If it is between -100 and $-50 \mathrm{nT}$ this indicates a moderate storm. The Dst index between -200 and $-100 \mathrm{nT}$ indicates a strong (intense) geomagnetic storm.

The characteristic storm at the intense level (Dst $=-223 \mathrm{nT}$ ) on March 17, 2015, has been analyzed. Figure 1 shows the OMNI data set from 00:00 UT on March 15, 2015, to 00:00 UT on March 19, 2015. The plot interval covers the storm day (March 17, 2015), 2 days before and 2 days after the storm $(120 \mathrm{~h})$. The St. Patrick's Day storm started on March 17 with CME. The solar wind pressure $(P)$ suddenly rose to one of the highest values of $17.91 \mathrm{nPa}$ 
(min.: 1.68; $\max .: 20.76 \mathrm{nPa}$ ), the magnetic field component $\left(B_{\mathrm{z}}\right)$ reached its maximum value of $20.1 \mathrm{nT}$, and the proton density $(N)$ increased to $38.51 / \mathrm{cm}^{3}$, one of its greatest values (min.: 2.7 ; max.: $40.1 \mathrm{~cm}^{-3}$ ) between 04:00 and 05:00 UT on March 17. The plasma flow speed $(v)$ rose to $609 \mathrm{~km} / \mathrm{s} 5 \mathrm{~h}$ later. It may be useful to observe variables at the maximum or minimum values before reviewing the literature. During the St. Patrick's Day storm, the Dst index reached the minimum value of $-223 \mathrm{nT}$ and the geomagnetic aurora electrojet index (AE) increased to reach its maximum value of $1570 \mathrm{nT}$. The magnetic field component of $B_{\mathrm{z}}$ decreased to $-18 \mathrm{nT}$, and ap index increased to $179 \mathrm{nT}$. The aurora appears in both hemispheres.

The parameters shown in Dst index, $B_{\mathrm{z}}$ magnetic field (nT), $E$ electric field $(\mathrm{mV} / \mathrm{m})$, proton density $N\left(1 / \mathrm{cm}^{3}\right)$, solar wind dynamic pressure $P(\mathrm{nPa})$, flow speed $v(\mathrm{~km} / \mathrm{s})$ and auroral electrojet AE (nT) for March 15-19, 2015, are obtained from NASA NSSDC OMNI data set.

Figure 1 is specifically described as follows. On March 17, 2015, at 22:00 (UT), when Dst is at its minimum $(-223 \mathrm{nT}), B_{\mathrm{z}}$ component increases to $-16.5 \mathrm{nT}$ and the electric field $E$ reaches $5.2 \mathrm{mV} / \mathrm{m}$. Meanwhile, ap index

Table 1 Descriptive analysis

\begin{tabular}{llllcc}
\hline & $\boldsymbol{N}$ & Minimum & Maximum & Mean & \multicolumn{2}{c}{ SD } \\
\hline$B_{\mathrm{z}}(\mathrm{nT})$ & 120 & -18.1 & 20.1 & -.317 & 6.8809 \\
$T(\mathrm{~K})$ & 120 & 21,425 & 912,227 & $142,900.23$ & $162,135.845$ \\
$N\left(1 / \mathrm{cm}^{3}\right)$ & 120 & 2.7 & 40.1 & 14.110 & 9.6623 \\
$V(\mathrm{~km} / \mathrm{s})$ & 120 & 298 & 683 & 485.23 & 123.119 \\
$P(\mathrm{nPa})$ & 120 & 1.68 & 20.76 & 5.6173 & 4.46443 \\
$E(\mathrm{mV} / \mathrm{m})$ & 120 & -9.97 & 10.57 & .5708 & 3.54970 \\
$\mathrm{Kp}$ & 120 & 3 & 77 & 37.50 & 19.355 \\
Dst (nT) & 120 & -223 & 56 & -43.40 & 63.249 \\
ap (nT) & 120 & 2 & 179 & 39.60 & 48.606 \\
AE (nT) & 120 & 17 & 1570 & 359.60 & 330.776 \\
\hline
\end{tabular}

reaches its maximum value $179 \mathrm{nT}$ by increasing, proton density $N$ is $8.61 / \mathrm{cm}^{3}$, plasma flow speed $v$ reaches one of the highest values of $558 \mathrm{~km} / \mathrm{s}$, and $\mathrm{AE}$ index catches $457 \mathrm{nT}$.

On March 17, 2015, at 14:00 (UT), when $B_{\mathrm{z}}$ component is minimum $(-18.1 \mathrm{nT})$, Dst index continues to decrease toward the minimum, the electric field $E$ reaches its own maximum value of $10.5 \mathrm{mV} / \mathrm{m}, \mathrm{AE}$ index reaches its own maximum value of $1570 \mathrm{nT}$, ap index reaches its maximum value $179 \mathrm{nT}$, and flow pressure $P$ takes its own one of the maximum values of $16.7 \mathrm{nPa}$.

On March 17, 2015, at 05:00 (UT), when $B_{\mathrm{z}}$ component is maximum $(20.1 \mathrm{nT})$, the electric field reaches its minimum value of $-9.9 \mathrm{mV} / \mathrm{m}$, proton density $N$ takes its own one of the maximum values of $38.51 / \mathrm{cm}^{3}, \mathrm{AE}$ index decreases and falls to one of the minimum values of $50 \mathrm{nT}$, and ap index continues to increase. As this happens Dst index reaches its maximum value $56 \mathrm{nT}$.

\section{Mathematical modeling}

The descriptive analysis values of the geomagnetic storm on March 2015 are displayed in Table 1. The reason for applying the descriptive analysis is to control the change interval of the variables and to acquire an idea about the standard deviations. The effect of the variable with a high standard deviation will be reduced. Accordingly, the most powerful variables statistically are $P, E, N, B_{\mathrm{z}}$, ap, respectively. It is expected that these variables will shape the storm. However, because of the causality principle and the cause-effect relationship, solar parameters are the causes and zonal geomagnetic indices are the results of the storm. The instant correlation samples between each coefficient of the storm are shown in Table 2. Pearson's correlation analysis is a parametrical statistical method which shows the direction, degree and importance of the relationship between variables. The correlation analysis is

Table 2 Pearson's correlation matrix for the storm variables

\begin{tabular}{|c|c|c|c|c|c|c|c|c|c|c|}
\hline & $B_{z}(\mathrm{nT})$ & $T(\mathrm{~K})$ & $N\left(1 / \mathrm{cm}^{3}\right)$ & $v(\mathrm{~km} / \mathrm{s})$ & $P(\mathrm{nPa})$ & $E(\mathrm{mV} / \mathrm{m})$ & $\mathrm{Kp}$ & Dst (nT) & ap (nT) & $\mathrm{AE}(\mathrm{nT})$ \\
\hline$B_{\mathrm{z}}(\mathrm{nT})$ & 1 & .038 & .171 & $-.316^{* *}$ & -.165 & $-.889^{* *}$ & $-.580^{* *}$ & $.618^{* *}$ & $-.712^{* *}$ & $-.687^{* *}$ \\
\hline$T(\mathrm{~K})$ & & 1 & -.133 & $.511^{* *}$ & $.378^{* *}$ & .084 & $.407^{* *}$ & $-.224^{*}$ & $.241^{* *}$ & $.244^{* *}$ \\
\hline$N\left(1 / \mathrm{cm}^{3}\right)$ & & & 1 & $-.682^{* *}$ & $.627^{* *}$ & -.130 & $-.274^{* *}$ & $.658^{* *}$ & -.068 & $-.277^{* *}$ \\
\hline$v(\mathrm{~km} / \mathrm{s})$ & & & & 1 & .060 & $.339 * *$ & $.702^{* *}$ & $-.742^{* *}$ & $.483^{* *}$ & $.582^{* *}$ \\
\hline$P(\mathrm{nPa})$ & & & & & 1 & $.272^{* *}$ & $.416^{* *}$ & .060 & $.532^{* *}$ & $.271^{* *}$ \\
\hline$E(\mathrm{mV} / \mathrm{m})$ & & & & & & 1 & $.648^{* *}$ & $-.616^{* *}$ & $.783^{* *}$ & $.757^{* *}$ \\
\hline Kp & & & & & & & 1 & $-.755^{* *}$ & $.887^{* *}$ & $.767^{* *}$ \\
\hline Dst (nT) & & & & & & & & 1 & $-.678^{* *}$ & $-.655^{* *}$ \\
\hline ap (nT) & & & & & & & & & 1 & $.754^{* *}$ \\
\hline$A E(n T)$ & & & & & & & & & & 1 \\
\hline
\end{tabular}

* and ${ }^{* *}$ Correlations are significant at the 0.05 level (two-tailed) and at the 0.01 level (two-tailed), respectively 
Table 3 KMO and Bartlett's test

\begin{tabular}{ll}
\hline Kaiser-Meyer-Olkin measure of sampling adequacy & .762 \\
Bartlett's test of sphericity & \\
Approx. Chi square & 1385.342 \\
df & 45 \\
Sig. & .000 \\
\hline
\end{tabular}

a complementary method of regression analysis. While the value between the two variables approaches \pm 1 , the relationship is strengthening. Physically, in this storm, the models in which take place $B_{\mathrm{z}}$ with ap, Dst, AE and $T$ with $v$ and $N$ with $v, P$ and $v$ with Kp, Dst, AE and $P$ with ap and $E$ with Kp, Dst, ap, AE may be considered as preferential.

KMO and Bartlett's test tables (Table 3) reveal the suitability of the data for factor analysis and show the strength of the relationship between variables. The Kaiser-Meyer-Olkin measure of sampling adequacy is a statistic and shows the commensurate of the variance in data that can be caused by main factors. High values (close to 1.0) imply that data are appropriate for a satisfactory factor analysis method. If the test value of variables is appropriate to the method, they exhibit a normal distribution. In order to deny the hypothesis $\mathrm{H}_{0}$ (null hypothesis), the significance of the test should be less than 0.05 . The attitudes of the data released as a result of a physical phenomenon can be determined by this test. If the data of the physical event indicate normal distribution, the variables show how they can be coordinated with each other and with the event. Thus, the linear or nonlinear relations can be discussed and models can be argued with obeying the mathematical approaches. As can be seen from Table 3, the variable set of this storm is suitable for factor analysis.
Factor analysis is used with the principle component analysis and varimax with Kaiser normalization for the rotation (converged in 3 iterations) to divide the variables into subgroups and to distinguish those who have the highest contribution to the event. In this analysis, which does not include composite variables, each variable is handled separately. The variables are examined in a more specific (by heap) way with basic component analysis. In Table 4, when the ten variables are substituted into the data reduction method, three maximum eigenvalues of the covariance matrix describe $88 \%$ of the total change, which means that it can be explained by modeling the $88 \%$ of the phenomenon with the variables at hand.

Varimax with Kaiser normalization method for the rotation matrix examines the linear grouping of variables of the event. The method approaching each variable as a factor indicates the contribution and weight of these factors in the linear clustering. Table 5 summarizes these weights.

Hence, these models can be written as follows with factor weights from Table 5 .

$$
\begin{aligned}
\text { Axes } 1= & -(0.920) B_{\mathrm{z}}-(0.001) T-(0.141) N \\
& +(0.400) v+(0.315) P+(0.938) E \\
& +(0.766) \mathrm{Kp}-(0.702) \mathrm{Dst} \\
& +(0.887) \mathrm{ap}+(0.828) \mathrm{AE}
\end{aligned}
$$

$$
\begin{aligned}
\text { Axes } 2= & (0.069) B_{\mathrm{z}}+(0.054) T+(0.956) N \\
& -(0.518) v+(0.805) P+(0.012) E \\
& -(0.070) \mathrm{Kp}+(0.543) \mathrm{Dst} \\
& +(0.137) \mathrm{ap}-(0.115) \mathrm{AE}
\end{aligned}
$$

Figure 2 illustrates the physical scattering of Dst, ap and $\mathrm{AE}$ zonal geomagnetic indices according to $B_{\mathrm{z}}, P, v$, $N$ solar wind parameters. In this work, the solar wind

Table 4 Total variance explained

\begin{tabular}{lllllll}
\hline Component & \multicolumn{2}{l}{ Initial eigenvalues } & & \multicolumn{2}{c}{ Extraction sums of squared loadings } \\
\cline { 2 - 6 } & Total & \% of variance & Cumulative \% & & Total & Cumulative \% \\
\hline 1 & 5.352 & 53.515 & 53.515 & 5.352 & 53.515 \\
2 & 2.049 & 20.487 & 74.002 & & 2.049 & 20.487 \\
3 & 1.432 & 14.325 & 88.327 & & 1.432 & 14.325 \\
\hline
\end{tabular}

Table 5 Rotated component matrix

\begin{tabular}{lcccccccccc}
\hline Component & $\boldsymbol{B}_{\mathbf{z}}(\mathrm{nT})$ & $\boldsymbol{T}(\mathrm{K})$ & $\boldsymbol{N}\left(\mathbf{1} / \mathbf{c m}^{\mathbf{3}}\right)$ & $\boldsymbol{v}(\mathbf{k m} / \mathbf{s})$ & $\boldsymbol{P}(\mathrm{nPa})$ & $E(\mathbf{m V} / \mathbf{m})$ & $\mathrm{Kp}$ & Dst (nT) & ap (nT) & AE (nT) \\
\hline 1 & -.920 & -.001 & -.141 & .400 & .315 & .938 & .766 & -.702 & .887 & .828 \\
2 & .069 & .054 & .956 & -.518 & .805 & .012 & -.070 & .543 & .137 & -.115 \\
\hline
\end{tabular}


Eroglu Earth, Planets and Space

(2019) $71: 26$

Page 6 of 12
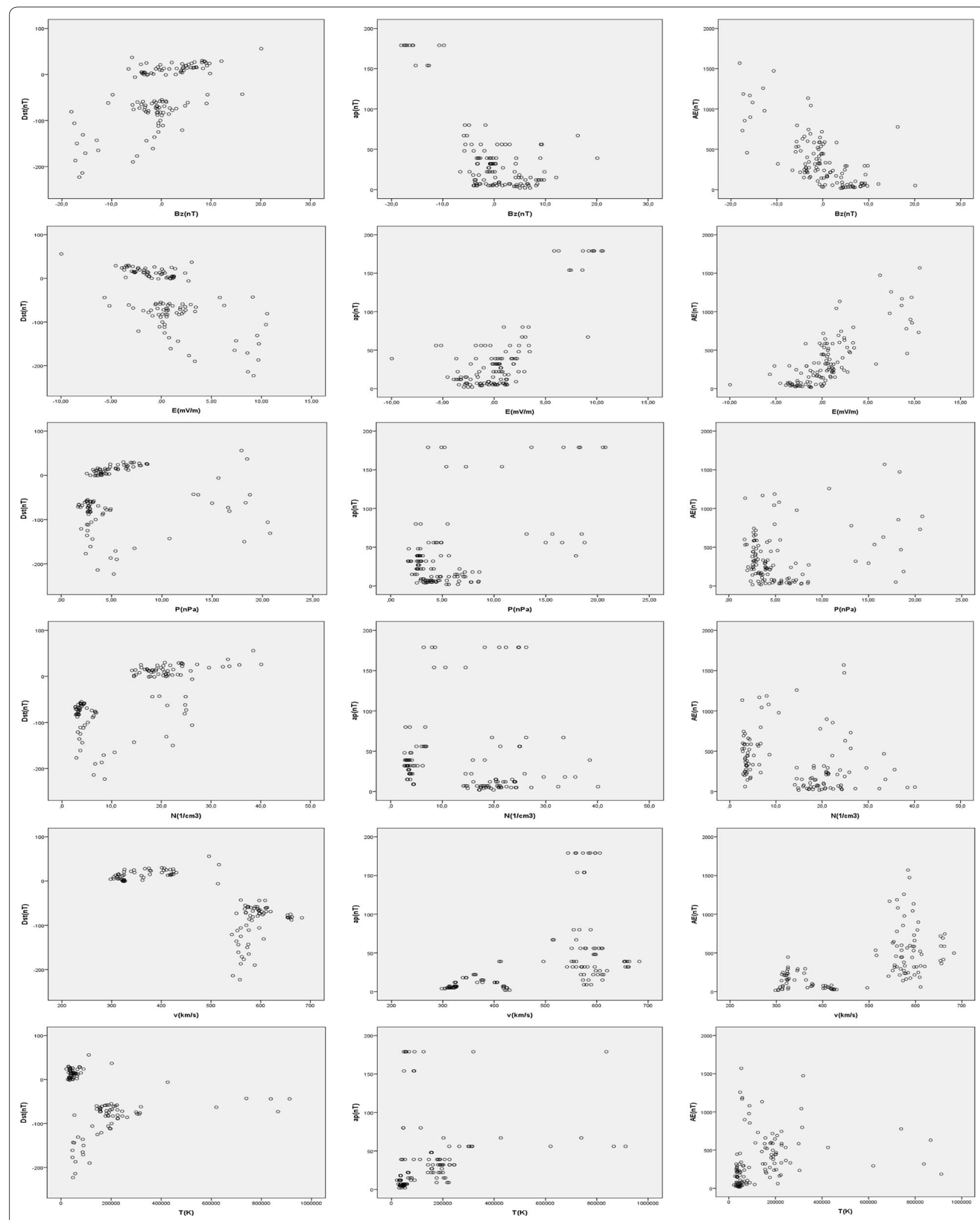

Fig. 2 Appearance between Dst, ap, $A E$ indices and $B_{z^{\prime}} E, P, N, v, T$ solar wind parameters. Relation between zonal geomagnetic indices (Dst, ap and $A E)$ and solar wind parameters (magnetic field component $\left(B_{z}\right)$, the electric field $(E)$, dynamic pressure $(P)$, proton density $(N)$, flow velocity $(v)$, temperature $(T)$ ) can be seen in Fig. 2. The relationships in the correlation are visualized 
propagation time from bow shock to Earth is not taken into account when Dst, ap and AE data from ground stations are used. As the time is too short to take these into account, one can find in Fig. 2 only the magnitudes of the values of $B_{z}, E, P, N, v, T$ solar wind parameters and Dst, ap, AE zonal geomagnetic indices, no matter how and when these arose with respect to each other.

According to Fig. 2, the physical reaction of zonal geomagnetic indices to the change in solar wind parameters in the storming process can be summarized as follows. The response of Dst to the magnetic field $B_{\mathrm{z}}$ component, the electric field $(E)$, proton density $(N)$ and temperature $(T)$ is linear, and the response to the dynamic pressure $(P)$ and flow speed $(v)$ is nonlinear. While the response of the ap index to $B_{z}$, electric field, flow speed and temperature is linear, its response to dynamic pressure and proton density is nonlinear. While the response of the AE index to $B_{z}$, electric field, dynamic pressure and temperature is linear, its response to proton density and flow speed is nonlinear.

\section{Linear and nonlinear model}

The regression model is:

$$
y_{i}=f_{i}(x, b)+\varepsilon_{i}=\sum_{j=1}^{n} b_{j} x_{j}+\varepsilon_{i}
$$

where $y_{i}$ is dependent variable, $x_{j}$ is $n$-dimensional independent variable, and $\varepsilon_{i}$ is error. $f_{i}(x, b)$ is called the expectation function for the regression model.

The sample covariance $s_{j k}^{2}$ is:

$$
s_{j k}^{2} \equiv \frac{\frac{1}{n-1} \sum_{i=1}^{n}\left[\frac{1}{\sigma_{i}^{2}}\left(x_{i j}-\bar{x}_{j}\right)\left(x_{i k}-\bar{x}_{k}\right)\right]}{\frac{1}{n} \sum_{i=1}^{n}\left(\frac{1}{\sigma_{i}^{2}}\right)}
$$

where $j, k=1,2 ; \sigma_{i}^{2}$ is the standard deviation; $n$ is the number of data points; and $\bar{x}_{j}$ is

$$
\bar{x}_{j} \equiv \frac{\sum_{i=1}^{n}\left(\frac{x_{i j}}{\sigma_{i}^{2}}\right)}{\sum_{i=1}^{n}\left(\frac{1}{\sigma_{i}^{2}}\right)} .
$$

The sample variance is given by $s_{j}^{2} \equiv s_{j j}^{2}$. The correlation coefficient can be expressed in terms of $r_{j k} \equiv \frac{s_{j k}^{2}}{s_{j} s_{k}}$. Square of multiple correlation coefficient $R^{2}$ is:

$$
R^{2} \equiv \sum_{j=1}^{n}\left(b_{j} \frac{s_{j y}^{2}}{s_{y}^{2}}\right)=\sum_{j=1}^{n}\left(b_{j} \frac{s_{j}}{s_{y}} r_{j y}\right) .
$$

$R^{2}$ is the percentage of the event defined by the model. The closer the $R^{2}$ is to one (1) in the established model, the greater the percentage of the model's description of the event is (Freund 1979; Saba et al. 1997).

Before discussing the binary relations of the zonal geomagnetic indices governed by the solar wind parameters, it would be appropriate to see the linear compositions of the indices. According to independent variables (solar wind parameters), the linear compounds of the dependent variables Dst and ap (zonal geomagnetic indices) are given in Tables 6, 7, 8 and 9, respectively. The coefficients can be seen from the tables. This table (Table 6) demonstrates how much of the residuals are explained by the variables in the linear regression model. One may realize that regression coefficients are

\begin{tabular}{|c|c|c|c|c|c|}
\hline \multirow[t]{2}{*}{ Model } & \multicolumn{2}{|c|}{$\begin{array}{l}\text { Unstandardized } \\
\text { coefficients }\end{array}$} & \multirow{2}{*}{$\begin{array}{l}\text { Standardized } \\
\text { coefficients } \\
\text { Beta }\end{array}$} & \multirow[t]{2}{*}{$t$} & \multirow[t]{2}{*}{ Sig. } \\
\hline & $B$ & SE & & & \\
\hline (Constant) & -244.925 & 73.544 & & -3.330 & .001 \\
\hline$B_{\mathrm{z}}(\mathrm{nT})$ & 3.497 & .670 & .471 & 5.217 & .000 \\
\hline$N(1 / \mathrm{cm} 3)$ & 10.321 & 2.396 & 1.617 & 4.308 & .000 \\
\hline$P(\mathrm{nPa})$ & -11.814 & 3.457 & -1.201 & -3.417 & .001 \\
\hline$v(\mathrm{~km} / \mathrm{s})$ & .256 & .123 & .265 & 2.078 & .042 \\
\hline
\end{tabular}

Table 6 ANOVA (analysis of variance)

\begin{tabular}{lccccc}
\hline Model & Sum of squares & df & Mean square & $\boldsymbol{F}$ & Sig. \\
\hline Regression & 131237.711 & 4 & $32,809.428$ & 26.445 & .000 \\
Residual & $83,124.164$ & 67 & 1240.659 & & \\
Total & $214,361.875$ & 71 & & & \\
\hline
\end{tabular}

Table 7 Regression coefficients

\begin{tabular}{|c|c|c|c|c|c|}
\hline \multirow[t]{2}{*}{ Model } & \multicolumn{2}{|c|}{$\begin{array}{l}\text { Unstandardized } \\
\text { coefficients }\end{array}$} & \multirow{2}{*}{$\begin{array}{l}\text { Standardized } \\
\text { coefficients } \\
\text { Beta }\end{array}$} & \multirow[t]{2}{*}{$t$} & \multirow[t]{2}{*}{ Sig. } \\
\hline & $B$ & SE & & & \\
\hline (Constant) & 24.093 & 4.244 & & 5.676 & .000 \\
\hline$E(\mathrm{mV} / \mathrm{m})$ & 4.653 & 1.477 & .349 & 3.151 & .002 \\
\hline$P(\mathrm{nPa})$ & 3.771 & .554 & .392 & 6.801 & .000 \\
\hline$B_{z}(n T)$ & -2.769 & .780 & -.382 & -3.551 & .001 \\
\hline
\end{tabular}

Table 8 ANOVA (analysis of variance)

\begin{tabular}{lcrccr}
\hline Model & Sum of squares & df & Mean square & $\boldsymbol{F}$ & Sig. \\
\hline Regression & $163,844.271$ & 3 & $54,614.757$ & 90.643 & .000 \\
Residual & $40,971.729$ & 68 & 602.525 & & \\
Total & $204,816.000$ & 71 & & & \\
\hline
\end{tabular}

Table 9 Regression coefficients 
significant. Table 7 shows the model of Dst index as: Dst $=-(244.925)+(3.497) B_{\mathrm{z}}+(10.321) N-(11.814) P$ $+(0.256) v$, where multiple determination coefficient $R$ is 0.782 .

Table 8 indicates that the model is significant, while Table 9 shows that the ap index is: ap $=(24.093)+(4.653) E+(3.771) P-(2.769) B_{\mathrm{z}}$, where multiple determination coefficient $R$ is 0.894 .

Physically, the magnetospheric activity is nonlinearly proportional to the proton density $(N)$ and plasma flow speed $(v)$ and linearly proportional to the interplanetary magnetic field (IMF) (Temerin and Li 2006; Agopyan 2010). Changes in solar wind pressure and CME cause nonlinear behavior, fluctuations and changes in the density of particles. The serious (>10 nT) orientation of the $B_{\mathrm{z}}$ component of the magnetic field to the southward for more than a few hours causes depression in the Dst and gets Dst directed to the negative direction. This depression on the Dst demonstrates a severe storm. Visualizing the response of such a storm to the solar wind parameters (especially $B_{\mathrm{z}}$ component) of the Dst index will give the reader a clearer idea. The linear and nonlinear models between the Dst, ap, AE indices and $B_{\mathrm{z}}$ are shown in Figs. 3, 4, 5 and Tables 10, 11, 12, respectively. The low correlation coefficients in these models should not be overlooked. Statistically, these are generally middle levels of models.

We know the importance of linear relationship between Dst and $B_{\mathrm{z}}$ step by step (Kane 2010). In addition to this approach, it is useful to investigate the relationship between ap and $B_{\mathrm{z}}$, and between $\mathrm{AE}$ and $B_{\mathrm{z}}$ using both linear and nonlinear models. Table 10 and Fig. 3 display the linear and quadratic relationships of the magnetic field component $B_{\mathrm{z}}$ with the Dst index. Dst $=-(41.602)+(5.677) B_{\mathrm{z}}$ where $R$ is 0.618 , and Dst $=-(38.016)+(5.418) B_{\mathrm{z}}-(0.078) B_{\mathrm{z}}^{2}$ where $R$ is 0.625 .

In Table 11 and Fig. 4, the linear and nonlinear relationships between the magnetic field component $B_{\mathrm{z}}$ and the ap index are presented. ap $=(38.007)-(5.029) B_{\mathrm{z}}$ where $R$ is 0.712, and ap $=(22.542)-(3.913) B_{\mathrm{z}}+(0.336) B_{\mathrm{z}}^{2}$ where $R$ is 0.896 . Mathematically, the height level of the nonlinear correlation with the $B_{\mathrm{z}}$ component and ap index should not be overlooked.

In Table 12 and Fig. 5, the linear and nonlinear relationships between the magnetic field component $B_{\mathrm{z}}$ and the $\mathrm{AE}$ index are presented. $\mathrm{AE}=(349.146)-(33.012) B_{z}$ where $R$ is 0.687 , and $\mathrm{AE}=(299.596)-(29.434) B_{\mathrm{z}}+(1.077) B_{\mathrm{z}}^{2}$ where $R$ is 0.733 .

Physically, fluctuations in the magnetic field indicate similar linear effects in flow pressure $(P)$ and proton density $(N)$, while ap index responds to these fluctuations nonlinearly. This nonlinear relationship and model are shown in Table 11 and Fig. 4. The nonlinear model is in the form of $P=a+b \ln$ ap $+c N$, where $a$, $b, c$ are constants. The analysis of variance values of the model are shown in Table 13. The magnitudes of coefficients are $a=-7.209, b=2.460$ and $c=0.376$. Table 14 shows that all parameter estimation is in the confidence
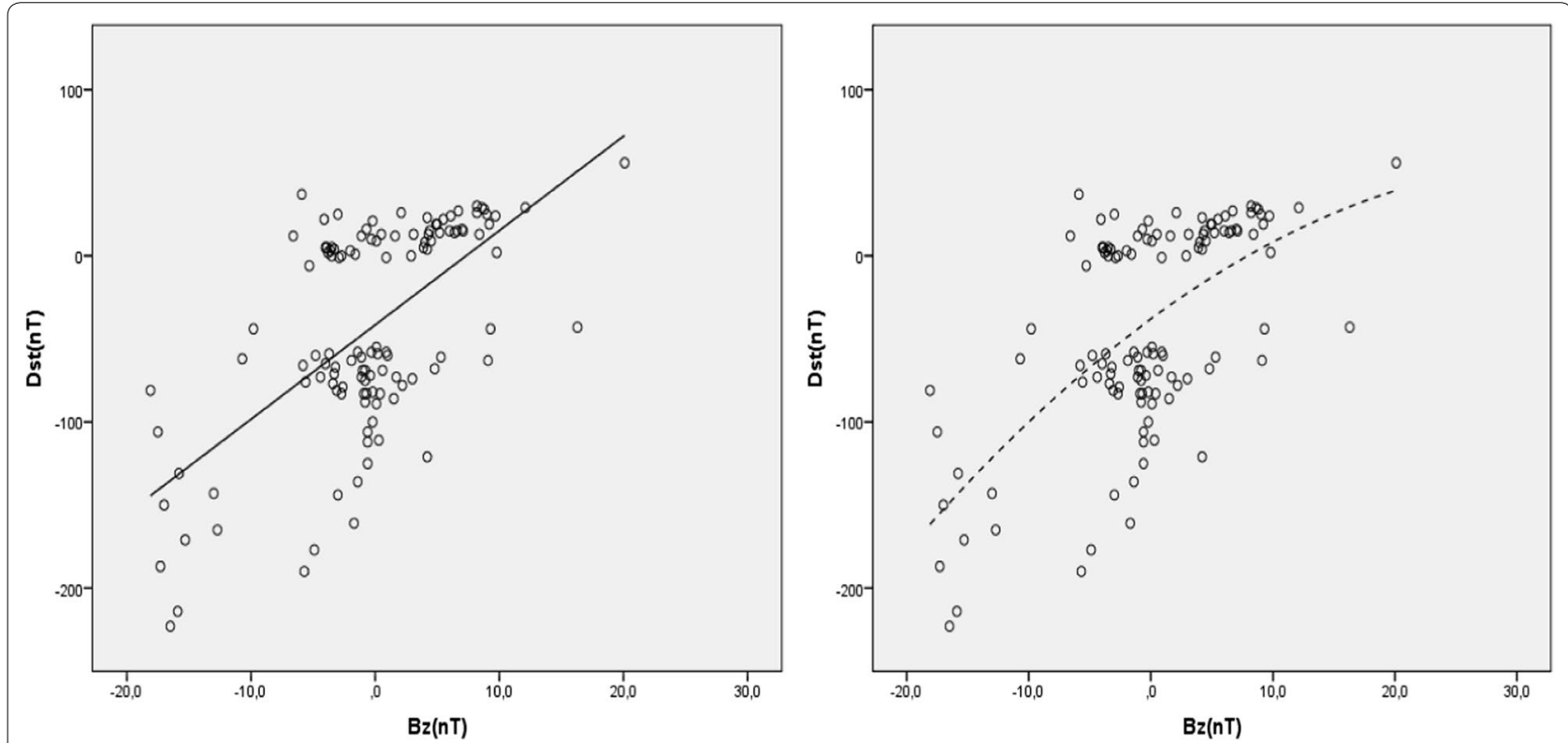

Fig. 3 Linear and quadratic relation of Dst and $B_{z}$. In Fig. 3, the linear and quadratic relationships of the magnetic field component $B_{z}$ with the Dst index are shown 

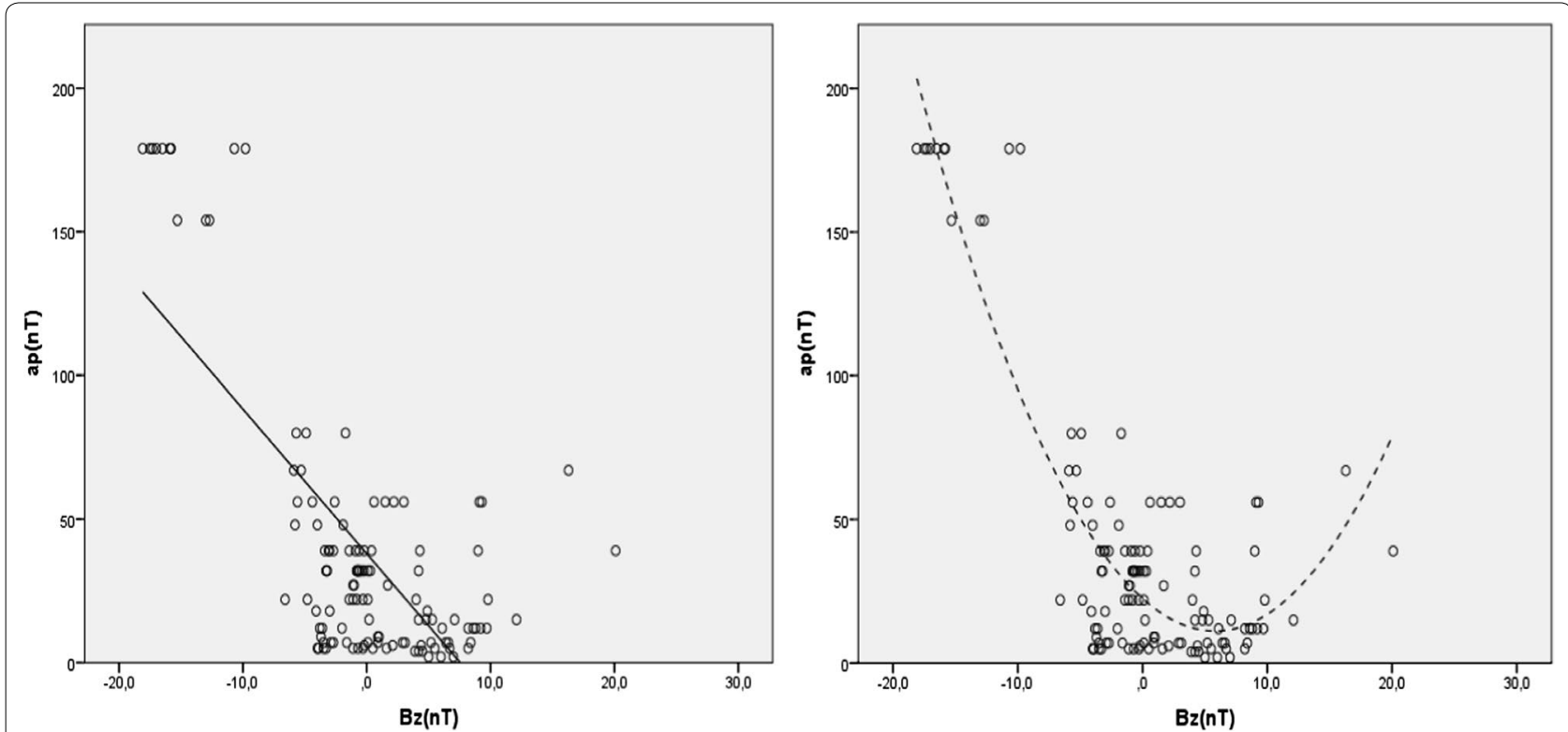

Fig. 4 Linear and quadratic relation between ap and $B_{z}$. In figure, the nonlinear relationship between the magnetic field component $B_{z}$ and the ap index can be seen
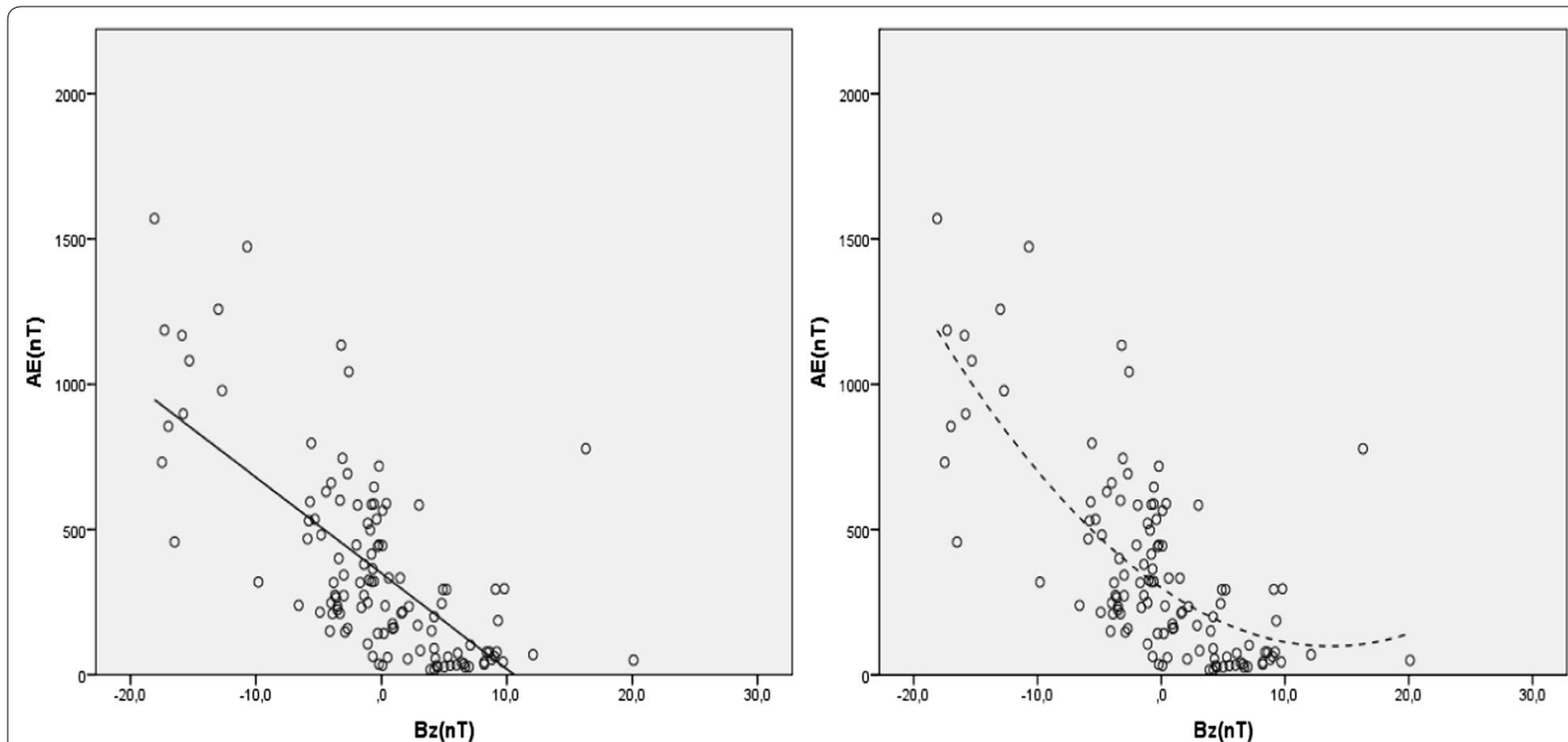

Fig. 5 Linear and quadratic relation of $A E$ and $B_{z}$. In figure, the nonlinear relationship between the magnetic field component $B_{z}$ and the $A E$ index can be seen

interval of $95 \%$. The model explaining this storm with $75.2 \%$ accuracy is

$$
P=-(7.209)+(2.460) \ln \text { ap }+(0.376) N .
$$

We believe that this nonlinear mathematical model allows a unique expression of pressure and density for plasma-dense medium (underground or atmosphere). 
Table 10 Regression coefficients

\begin{tabular}{|c|c|c|c|c|c|}
\hline & \multicolumn{2}{|c|}{ Unstandardized coefficients } & \multirow{2}{*}{$\begin{array}{l}\text { Standardized coefficients } \\
\text { Beta }\end{array}$} & \multirow[t]{2}{*}{$t$} & \multirow[t]{2}{*}{ Sig. } \\
\hline & $B$ & SE & & & \\
\hline$B_{\mathrm{z}}(\mathrm{nT})$ & 5.677 & .665 & .618 & 8.532 & .000 \\
\hline \multirow[t]{3}{*}{ (Constant) } & -41.602 & 4.565 & & -9.114 & .000 \\
\hline & \multicolumn{2}{|c|}{ Unstand. coeff. } & Stand. coeff. & $t$ & Sig. \\
\hline & $B$ & SE & Beta & & \\
\hline$B_{\mathrm{z}}(\mathrm{nT})$ & 5.418 & .691 & .589 & 7.846 & .000 \\
\hline$B_{Z}^{2}(\mathrm{nT})$ & -.078 & .058 & -.101 & -1.344 & .081 \\
\hline (Constant) & -38.016 & 5.274 & & -7.209 & .000 \\
\hline
\end{tabular}

Table 11 Regression coefficients

\begin{tabular}{|c|c|c|c|c|c|}
\hline & \multicolumn{2}{|c|}{ Unstandardized coefficients } & \multirow{2}{*}{$\begin{array}{l}\text { Standardized coefficients } \\
\text { Beta }\end{array}$} & \multirow[t]{2}{*}{$t$} & \multirow[t]{2}{*}{ Sig. } \\
\hline & $B$ & SE & & & \\
\hline$B_{\mathrm{z}}(\mathrm{nT})$ & -5.029 & .457 & -.712 & -11.014 & .000 \\
\hline \multirow[t]{3}{*}{ (Constant) } & 38.007 & 3.132 & & 12.134 & .000 \\
\hline & \multicolumn{2}{|c|}{ Unstand. coeff. } & Stand. coeff. & $t$ & Sig. \\
\hline & $B$ & Std. Err & Beta & & \\
\hline$B_{\mathrm{z}}(\mathrm{nT})$ & -3.913 & .302 & -.554 & -12.970 & .000 \\
\hline$B_{Z}^{2}(n T)$ & .336 & .025 & .567 & 13.273 & .000 \\
\hline (Constant) & 22.542 & 2.304 & & 9.786 & .000 \\
\hline
\end{tabular}

Table 12 Regression coefficients

\begin{tabular}{|c|c|c|c|c|c|}
\hline & \multicolumn{2}{|c|}{ Unstandardized coefficients } & \multirow{2}{*}{$\begin{array}{l}\text { Standardized coefficients } \\
\text { Beta }\end{array}$} & \multirow[t]{2}{*}{$t$} & \multirow[t]{2}{*}{ Sig. } \\
\hline & $B$ & SE & & & \\
\hline$B_{\mathrm{z}}(\mathrm{nT})$ & -33.012 & 3.217 & -.687 & -10.262 & .000 \\
\hline \multirow[t]{3}{*}{ (Constant) } & 349.146 & 22.066 & & 15.823 & .000 \\
\hline & \multicolumn{2}{|c|}{ Unstand. coeff. } & Stand. coeff. & $t$ & Sig. \\
\hline & $B$ & SE & Beta & & \\
\hline$B_{z}(\mathrm{nT})$ & -29.434 & 3.148 & -.612 & -9.350 & .000 \\
\hline$B_{\mathrm{z}}^{2}(\mathrm{nT})$ & 1.077 & .264 & .267 & 4.075 & .000 \\
\hline (Constant) & 299.596 & 24.039 & & 12.463 & .000 \\
\hline
\end{tabular}

\section{Conclusion}

The St. Patrick's Day geomagnetic storm is the most severe storm in the 24th solar cycle. Every model that can be established about the storm should be meticulously analyzed. In particular, the mathematical models involving magnetic field, solar wind pressure and proton density give ideas of the dynamic nature of the different plasmatic structures. This study has focused on the March 2015 severe storm by using the St. Patrick's Day severe storm data $(120 \mathrm{~h})$. The data have been analyzed mathematically, and the models have been established. The models strictly obeying to physical principles have been consistently introduced in this study as well. These models support the previous studies of the author. The zonal geomagnetic indices produced by solar wind parameters are displayed in the 
Table 13 ANOVA (analysis of variance)

\begin{tabular}{lcrc}
\hline Source & Sum of squares & df & Mean squares \\
\hline Regression & 2494.129 & 3 & 831.376 \\
Residual & 384.379 & 117 & 3.285 \\
Uncorrected total & 2878.509 & 120 & \\
Corrected total & 1209.483 & 119 & \\
\hline
\end{tabular}

Table 14 Parameter estimates

\begin{tabular}{lrrrr}
\hline Parameter & Estimate & SE & \multicolumn{2}{c}{$\mathbf{9 5 \% \text { Confidence interval }}$} \\
\cline { 3 - 5 } & & & Lower bound & Upper bound \\
\hline$a$ & -7.209 & .762 & -8.719 & -5.700 \\
$b$ & 2.460 & .189 & 2.086 & 2.834 \\
$c$ & .376 & .022 & .332 & .420 \\
\hline
\end{tabular}

correlations based on the cause-effect relationship. Graphs and tables have presented the relationship between zonal geomagnetic indices and solar wind parameters, as well as their interactions with each other. All results are in the $95 \%$ confidence interval. Even though some models have discussed the various results of the storm with low precision (statistically), they have been included in this paper for comparison.

\section{Authors' contributions}

The manuscript has one author. Data are collected and analyzed by the author. All interpretations and explanations belong to the author. The author read and approved the final manuscript.

\section{Acknowledgements}

I thank the NASA CDA Web for OMNI Database (http://themis.igpp.ucla.edu/ software.shtml) and Kyoto World Data Center for providing AE index and Dst index. I acknowledge the usage of ap and Kp index from the National Geophysical Data Center. The Dst index and AE data were provided by the World Data Center for Geomagnetism at Kyoto University. I would like to thank Kirklareli University, Professor Ali Yigit, Dereyayla and Akyuz families for their valuable support for this study. I thank Professor Huishan S. Fu for his very helpful comments, corrections and suggestions. I thank Professor Halil Atabay for very supportive corrections.

\section{Competing interests}

The author declares no competing interests.

\section{Availability of data and materials}

The data used in this article are available at the Data Center of NASA https:// omniweb.gsfc.nasa.gov/form/dx1.html

Ethics approval and consent to participate

This study does not require ethical approval.

\section{Funding}

We declare no funding.

\section{Publisher's Note}

Springer Nature remains neutral with regard to jurisdictional claims in published maps and institutional affiliations.

Received: 13 March 2018 Accepted: 17 February 2019

Published online: 01 March 2019

\section{References}

Ak N, Eroglu E, Guney I (2012) Statistical analysis of soil heavy metals of Istanbul children playgrounds. Energy Educ Sci Technol Part A 28(2):1151-1158

Akasofu SI (1964) The development of the auroral substorm. Planet Space Sci 12(4):273-282

Agopyan H (2010) İstanbul İyonküresinde Ölçülen Şiddetli Manyetik Fırtına Etkilerine Jeofizikten Bir Örnek. Tubav Bilim Dergisi 3:315 (in Turkish)

Astafyeva E, Zakharenkova I, Förster M (2015) lonospheric response to the 2015 St. Patrick's Day storm: a global multi-instrumental overview. J Geophys Res 120(10):9023-9037. https://doi.org/10.1002/2015ja021629

Baker DN, Klimas AJ, McPherron RL, Büchner J (1990) The evolution from weak to strong geomagnetic activity: an interpretation in terms of deterministic chaos. Geophys Res Lett 17(1):41-44

Baker DN, Jaynes AN, Kanekal SG, Foster JC, Erickson PJ, Fennell JF, Blake JB, Zhao H, Li X, Elkington SR, Henderson MG, Reeves GD, Spence HE, Kletzing CA, Wygant JR (2016) Highly relativistic radiation belt electron acceleration, transport, and loss: large solar storm events of March and June 2015. J Geophys Res 121(7):6647-6660. https://doi.org/10.1002/2016J A022502

Blanc M, Richmond AD (1980) The ionospheric disturbance dynamo. J Geophys Res 85(A4):1669-1686. https://doi.org/10.1029/JA085iA04p01669

Burton RK, McPherron RL, Russell CT (1975) An empirical relationship between interplanetary conditions and Dst. J Geophys Res 80(31):4204-4214

Celebi M, Ozdemir Z, Eroglu E, Guney I (2014) Statistically defining optimal conditions of coagulation time of skim milk. J Chem Soc Pak 36(1):1-5

Chen CH, Lin CH, Matsuo T, Chen WHJ (2016) lonosphere data assimilation modeling of 2015 St. Patrick's Day geomagnetic storm. Geophys Res 121(11):11549-11559. https://doi.org/10.1002/2016ja023346

Cherniak I, Zakharenkova I (2015) Dependence of the high-latitude plasma irregularities on the auroral activity indices: a case study of 17 March 2015 geomagnetic storm. Earth Planets Space 67:151. https://doi.org/10.1186/ s40623-015-0316-x

Cherniak I, Zakharenkova I, Redmon RJ (2015) Dynamics of the high-latitude ionospheric irregularities during the 17 March 2015 St. Patrick's Day storm: ground-based GPS measurements. Sp Weather 13(9):585-597. https://doi.org/10.1002/2015sw001237

Dungey JW (1961) Interplanetary magnetic field and the auroral zones. Phys Rev Lett 6:47. https://doi.org/10.1103/PhysRevLett.6.47

Eroglu E (2018) Mathematical modeling of the moderate storm on 28 February 2008. Newast 60:33-41. https://doi.org/10.1016/j.newast.2017.10.002

Eroglu E, Aksoy S, Tretyakov OA (2012) Surplus of energy for time-domain waveguide modes. Energy Educ Sci Technol 29(1):495-506

Eroglu E, Ak N, Guney I, Sener E (2016) Component analysis of the different fish samples containing heavy metals in Istanbul Bosporus. Fresenius Environ Bull 25(1):292-299

Elliott HA, Jahn JM, David JMC (2013) The Kp index and solar wind speed relationship: insights for improving space weather forecasts. Sp Weather 11(6):339-349. https://doi.org/10.1002/swe.20053

Freund JE (1979) Modern elementary statistics, 5th edn. Prentice Hall, Arizona

Fu HS, Tu JP, Song JB Cao, Reinisch BW, Yang B (2010a) The nightside-todayside evolution of the inner magnetosphere: imager for magnetopause-to-aurora global exploration radio plasma imager observations. J Geophys Res 115:A04213. https://doi.org/10.1029/2009JA014668

Fu HS, Tu JJ, Cao B, Song P, Reinisch BW, Gallagher DL, Yang B (2010b) IMAGE and DMSP observations of a density trough inside the plasmasphere. $J$ Geophys Res 115:A07227. https://doi.org/10.1029/2009JA015104

Fu HS, Khotyaintsev YV, André M, Vaivads A (2011) Fermi and betatron acceleration of suprathermal electrons behind dipolarization fronts. Geophys Res Lett 38(16):L16104. https://doi.org/10.1029/2011GL048528 
Fu HS, Khotyaintsev YV, Vaivads A, André M, Huang SY (2012) Occurrence rate of earthward-propagating dipolarization fronts. Geophys Res Lett 39(10):L10101. https://doi.org/10.1029/2012GL051784

Fu HS et al (2013a) Dipolarization fronts as a consequence of transient reconnection: In situ evidence. Geophys Res Lett 40(23):6023-6027. https://doi. org/10.1002/2013GL058620

Fu HS, Khotyaintsev YV, Vaivads A, Retinò A, André M (2013b) Energetic electron acceleration by unsteady magnetic reconnection. Nat Phys 9(7):426-430. https://doi.org/10.1038/nphys2664

Fu HS et al (2014) Whistler-mode waves inside flux pileup region: structured or unstructured? J Geophys Res 119(11):9089-9100. https://doi. org/10.1002/2014JA020204

Fu HS, Vaivads A, Khotyaintsev YV, Olshevsky V, André M, Cao JB, Huang SY, Retinò A, Lapenta G (2015) How to find magnetic nulls and reconstruct field topology with MMS data? J Geophys Res Space Phys 120(5):3758-3782. https://doi.org/10.1002/2015JA021082

Fu HS, Vaivads A, Khotyaintsev YV, André M, Cao JB, Olshevsky V, Eastwood JP, Retinò A (2017) Intermittent energy dissipation by turbulent reconnection. Geophys Res Lett 44(1):37-43. https://doi.org/10.1002/2016GL0717 87

Gilmore M, Yu CX, Rhodes TL, Peebles WA (2002) Investigation of rescaled range analysis, the Hurst exponent, and long-time correlations in plasma turbulence. Phys Plasmas 9(4):1312. https://doi.org/10.1063/1.1459707

Gvishiani AD, Sidorov RV, Lukianova RY, Soloviev AA (2016) Geomagnetic activity during St Patrick's Day storm inferred from global and local indicators. RJES. https://doi.org/10.2205/2016es000593

Gonzalez WD, Joselyn JA, Kamide Y, Kroehl HW, Rostoker G, Tsurutani BT, Vasyliunas VM (1994) What is a geomagnetic storm? J Geophys Res 99(A4):5771-5792. https://doi.org/10.1029/93JA02867

Gonzalez WD, Tsurutani BT, Gonzalez AL (1999) Interplanetary origin of geomagnetic storms. Space Sci Rev 88:529-562. https://doi. org/10.1023/A:1005160129098

Hanslmeier A (2007) The sun and space weather, 2nd edn. In: Astrophysics and space science. Springer

Joshi NC et al (2011) Relationship between interplanetary field/plasma parameters with geomagnetic indices and their behavior during intense geomagnetic storms. Newast 16:366. https://doi.org/10.1016/j.newas t.2011.01.004

Kamide Y, Yokoyama N, Gonzalez W, Tsurutani BT, Daglis IA, Brekke A, Masuda S (1998) Two-step development of geomagnetic storms. JGR Space Phys 103:6917. https://doi.org/10.1029/97JA03337

Kane RP (2010) Relationship between the geomagnetic Dst(min) and the interplanetary $B_{z}(\mathrm{~min})$ during cycle 23. Planet Space Sci 58(3):392-400. https://doi.org/10.1016/j.pss.2009.11.005

Lin J, Forbes TG (2000) Effects of reconnection on the coronal mass ejection process. J Geophys Res 105(A2):2375-2392. https://doi. org/10.1029/1999JA900477
Loewe CA, Prölss GW (1997) Classification and mean behavior of magnetic storms. J Geophys Res 102(A7):14209-14213

Manoharan PK, Subrahmanya CR, Chengalur JN (2017) Space weather and solar wind studies with OWFA. J Astrophys Astron 38:16. https://doi. org/10.1007/s12036-017-9435-Z

Nava B, Zuluaga JR, Cuartas KA, Kashcheyev A, Orué YM, Radicella SM, Mazaudier CA, Fleury R (2016) Middle- and low-latitude ionosphere response to 2015 St. Patrick's Day geomagnetic storm. J Geophys Res 121(4):3421-3438. https://doi.org/10.1002/2015ja022299

Nayak C, Tsai LC, Su SY, Galkin IA, Tan ATK, Nofri E, Jamjareegulgarn P (2016) Peculiar features of the low-latitude and midlatitude ionospheric response to the St. Patrick's Day geomagnetic storm of 17 March 2015. J Geophys Res 121(8):7941-7960. https://doi.org/10.1002/2016ja022489

Rathore B, Gupta D, Parashar K (2014) Relation between solar wind parameter and geomagnetic storm condition during cycle-23. Int J Geosci. https:// doi.org/10.4236/ijg.2014.513131

Saba FMM, Gonzalez WD, Gonzalez ALC (1997) Relationships between the AE, ap and Dst indices near solar minimum (1974) and at solar maximum (1979). Ann Geophys 15(10):1265-1270. https://doi.org/10.1007/s0058 5-997-1265-X

Sibeck DG, Lopez RE, Roelof EC (1991) Solar wind control of the magnetopause shape, location, and motion. J Geophys Res Space Phys 96(A4):5489-5495. https://doi.org/10.1029/90JA02464

Subrahmanya CR, Prasad P, Girish BS, Somashekar R, Manoharan PK, Mittal AK (2017) The receiver system for the Ooty wide field array. J Astrophys Astron 38:11. https://doi.org/10.1007/s12036-017-9434-0

Sugiura M (1964) Hourly values of the equatorial Dst for IGY, vol 35. NASA, Goddard Space Flight Center, Greenbelt, MD, p 49

Temerin M, Li X (2002) A new model for the prediction of Dst on the basis of the solar wind. J Geophys Res 107(A12):1472. https://doi. org/10.1029/2001JA007532

Temerin M, Li X (2006) Dst model for 1995-2002. J Geophys Res. https://doi. org/10.1029/2005JA011257

Tretyakov OA, Erden F (2008) Temporal cavity oscillations caused by a wide band waveform. Prog Electromagn Res B Pier B 6:183-204. https://doi. org/10.2528/PIERB08031222

Tsyganenko NA, Singer HJ, Kasper JC (2003) Storm-time distortion of the inner magnetosphere: How severe can it get? J Geophys Res 108(A5):1209. https://doi.org/10.1029/2002JA009808

Wu CC, Leping RP (2016) Relationships among geomagnetic storms, interplanetary shocks, magnetic clouds, and sunspot number during 1995-2012. Sol Phys 291(1):265-284. https://doi.org/10.1007/s11207-015-0806-9

Zic T, Vrsnak B, Temmer M (2015) Heliospheric propagation of coronal mass ejections drag-based model fitting. ApJS 218:32. https://doi. org/10.1088/0067-0049/218/2/32

\section{Submit your manuscript to a SpringerOpen ${ }^{\odot}$ journal and benefit from:}

- Convenient online submission

- Rigorous peer review

- Open access: articles freely available online

- High visibility within the field

- Retaining the copyright to your article

Submit your next manuscript at $\boldsymbol{\nabla}$ springeropen.com 